\title{
Um estudo da disciplina História da Educação e suas contribuições para a formação docente no Brasil
}

\author{
Mônica Soares Rodrigues ${ }^{1}$ \\ Raimara Gonçalves Pereira ${ }^{2}$ \\ Viviane Bernadeth Gandra Brandão ${ }^{3}$
}

\begin{abstract}
Resumo: Este estudo teve como objetivo levantar dados referentes à presença da disciplina História da Educação e sua importância nos cursos de formação de professores no Brasil. Do ponto de vista da abordagem, optou-se por realizar uma pesquisa de natureza bibliográfica, fundamentada nos princípios da investigação histórica que se sustenta em uma visão de totalidade, conforme aponta a concepção histórico crítica. Para alcançar a consecução dessas pretensões, apoiou-se em teóricos como: Saviani (2005), Gatti (2006), Carvalho (2005), Nunes (2006), Aranha (1996), Noronha (1998), Tanuri (2000), entre outros que entendem que esta é uma disciplina imprescindível nos cursos de formação de professores. Tendo em vista que coloca em evidência questões indispensáveis à formação docente, ela se aproxima e dialoga com componentes do currículo dos cursos. A sua presença proporciona ao futuro professor uma maior fundamentação para discutir diferentes momentos históricos e a organização educacional em diversos contextos.
\end{abstract}

Palavras-chave: Formação Docente. História da Educação. Ensino Superior.

\section{A study of the discipline History of Education and contributions to teaching training in Brazil}

\begin{abstract}
This study aimed to raise data regarding the presence of the History of Education discipline and its importance in teacher training courses in Brazil. From the point of view of the approach, it was decided to carry out a bibliographical research, based on the principles of historical research that is based on a vision of totality, as indicated by the critical historical conception. To achieve these claims, it relied on theorists such as: Saviani (2005), Gatti (2006), Carvalho (2005), Nunes (2006), Aranha (1996), Noronha (1998), Tanuri (2000), among others who understand that this is an essential discipline in teacher training courses. Given that it highlights issues that are essential to teacher education, it approaches and dialogues with components of the course curriculum. Their presence provides the future teacher with a greater foundation to discuss different

\footnotetext{
${ }^{1}$ Graduada em Pedagogia pela Universidade Estadual de Montes Claros (Unimontes). Minas Gerais, Brasil. E-mail: monicasrodrigues05@gmail.com. Orcid: https://orcid.org/0000-0003-0481-4872.

${ }^{2}$ Mestra em Desenvolvimento Social pela Universidade Estadual de Montes Claros (Unimontes). Minas Gerais, Brasil. E-mail: rhaymara2009@yahoo.com.br. Orcid: https://orcid.org/0000-0003-0377-3300.

${ }^{3}$ Doutora em Educação. Professora do Programa de Pós-Graduação em Educação da Universidade Estadual de Montes Claros (Unimontes). Minas Gerais, Brasil. E-mail: viviane.gandra1@ @otmail.com. Orcid: https://orcid.org/0000-0001-5237-4504.
} 
historical moments and the educational organization in different contexts.

Keywords: Teacher Training. History of Education. University Education.

\section{Un estudio de la disciplina Historia de la Educación y las contribuciones a la formación docente en Brasil}

Resumen: Este estudio tuvo como objetivo recabar datos sobre la presencia de la disciplina Historia de la Educación y su importancia en los cursos de formación docente en Brasil. Desde el punto de vista del enfoque, se decidió realizar una investigación bibliográfica, basada en los principios de la investigación histórica que se sustenta en una visión de totalidad, como lo indica la concepción histórica crítica. Para lograr estas afirmaciones se apoyó en teóricos como: Saviani (2005), Gatti (2006), Carvalho (2005), Nunes (2006), Aranha (1996), Noronha (1998), Tanuri (2000), entre otros que comprender que se trata de una disciplina imprescindible en los cursos de formación docente. Dado que resalta temas que son esenciales para la formación del profesorado, aborda y dialoga con componentes más amplios del plan de estudios del curso. Su presencia proporciona al futuro docente una mayor base para discutir diferentes momentos históricos y la organización educativa en diferentes contextos.

Palabras clave: Formación de Profesores. Historia de la Educación. Enseñanza Superior.

\section{Introdução}

O presente estudo, oriundo do campo da educação, objetiva apresentar resultados de pesquisa realizada na área da História da Educação com fundamentação teórica que acena para fatos que evidenciam a importância dos debates acerca das práticas pedagógicas nos cursos de formação de professores. No dia a dia em sala de aula, em que estas práticas são vivenciadas, constantemente vem à tona problemas decorrentes das mais variadas ordens, que se encontram ocultos em meio às relações entre professoraluno-conhecimento, dentro do processo educacional.

Diante dessa realidade se faz necessário promover espaços de discussões acerca de temas que podem estar diretamente relacionados com os problemas enfrentados no âmbito educacional, mais especificamente na formação de professores, onde se busca pensar as contradições que se apresentam no processo de ensino-aprendizagem no ambiente escolar.

É no mencionado contexto, que a disciplina História da Educação pode ser entendida como espaço de contribuições para que o acadêmico compreenda a realidade como produto de um processo histórico construído ao longo dos tempos. Desta forma, compreende-se que o estudo da História da Educação poderá influenciar, dependendo do enfoque que lhe é atribuído, de maneira positiva ou negativa no processo de desenvolvimento da visão educacional que pode estar adequada ou não ao processo de 
emancipação do sujeito.

Por se compor um espaço de análise do contexto sócio histórico das práticas educativas, a História de Educação ao longo da sua consolidação como campo do conhecimento apresenta diferentes abordagens teóricas e metodológicas, estando os seus fundamentos relacionados a diferentes paradigmas presentes no seu corpo disciplinar, e que por sua vez se tornam motivos de inquietações que comungam com ideias de diversos pesquisadores na área, como Warde (1998, 1990), que entende que a História da Educação está marcada pela pragmatização.

E assim, prevalece o entendimento de que a disciplina, ao estabelecer relação mecânica entre o passado, o presente e o futuro, possibilitaria, mediante o estudo do passado, compreender o presente e intervir no futuro, evitando que se cometessem os mesmos equívocos dos antepassados.

Segundo Gatti (2007), no que se refere à concepção do cenário nacional do ensino de História da Educação, este encontra vivenciado por meio de práticas coerentes com a experiência mundial enquanto tendência para o conhecimento prático tecnicista. Entendese que esta não contribui com a formação de profissionais para a educação que compreendam a importância do conhecimento dos diversos fatos e fenômenos históricos que são negligenciados pelas políticas sociais vigentes. Elementos estes necessários ao processo de emancipação do sujeito social.

Diante das questões aqui postas até então, é que se justifica a intenção de pesquisar a temática ora apresentada, por meio de estudos bibliográficos, tomando como base pesquisadores que se ocupam da pesquisa na área de História da Educação, como Lombardi, Saviani, Gatti Junior, Nunes, Faria Filho, Carvalho, dentre tantos outros.

Desta forma, este estudo assumiu o desafio de investigar a presença da História da Educação nos cursos de formação de professores, a fim de identificar se a sua influência na educação brasileira está sendo coerente com necessidade de oferecer ao acadêmico, futuro professor, uma formação que lhe possibilite desenvolver uma consciência crítica.

É perante o contexto aqui apresentado, que esta proposta sustentou-se na ideia da necessidade de realizar um levantamento bibliográfico acerca da formação de professores no Brasil e a presença da disciplina História da Educação na trajetória da formação docente. 
Desta forma, entende-se que os professores formados através dos cursos de licenciaturas, muitas vezes são influenciados pelos conteúdos adquiridos na graduação, assim, a maioria ao exercitarem sua prática em sala de aula acabam se tornando difusores de valores e ideologias que se hegemonizam no contexto educacional a serviço das políticas públicas vivenciadas no decorrer da história dessa região.

Diante do exposto a presente proposta de pesquisa busca responder a seguinte questão: Qual a valorização da disciplina História da Educação, bem como, o seu ensino nos cursos de formação de professores?

A hipótese é que a ausência da disciplina na formação docente, traz em si expressivos prejuízos para os profissionais da educação. Pois na maioria dos cursos de licenciatura, a disciplina em questão, quando é estudada, era vista apenas em um período, com uma carga horária reduzida, o que impossibilita estudar criteriosamente um determinado conteúdo, a fim de problematizá-lo, em direção a uma perspectiva de práxis. Condição indispensável ao processo de emancipação do sujeito. E neste caso, do futuro professor.

Este estudo subsidia também, reflexão a respeito do pouco espaço para a discussão da História da Educação, pois entende-se que por ser uma disciplina indispensável na formação de professores. Onde está formação precisa ser pensada e planejada de forma a permitir ao professor em formação uma visão ampla e crítica dos acontecimentos educacionais. Por isso, o ensino da História da Educação quando abordado em perspectiva ampla e crítica, pode se tornar espaço de emancipação nos cursos de formação de professores, visto que o seu ensino possibilita o estudo dos fatos e fenômenos sóciohistórico, de modo a fundamentar decisões que objetiva transpor o estado acrítico imposto pela ideologia dominante.

Esta proposta de estudo tem como intuito colaborar, mesmo que de modo singular, com a ampliação das reflexões na área, que poderão contribuir para um novo modo de pensar a História da Educação enquanto uma importante disciplina dentro dos cursos de formação de professores.

Assim, consequentemente, promoverá a efetivação da relação ensino-pesquisaextensão, por meio da ampliação, especialmente, entre os acadêmicos do debate acerca da importância dos elementos da História da Educação no processo de formação docente. Desta maneira, pondera-se que o estudo, provoque o interesse dos pesquisadores em 
tomar a temática como objeto de estudo em seus trabalhos.

Dessa maneira, com o olhar na direção metodológica pautada nas leituras dos autores supracitados, este estudo encontra-se organizado da seguinte forma: primeiro realiza-se uma breve abordagem a respeito da formação de professores no Brasil. Em seguida elenca-se, elementos teóricos no campo da formação de professores por meio dessa disciplina, com intuito de problematizar o seu ensino. Também se referia à essência do trabalho docente e a importância do ensino de História da Educação na formação de professores como condição de construção de um professor emancipado.

\section{Formação de professores no Brasil}

Inicia-se, essa reflexão, a partir da discussão acerca do processo de formação de professores no Brasil. Pondera-se que, na história da formação de professores do século XIX, se configuraram dois modelos contrapostos, a fim de resolver o problema da instrução popular. Foram instalados em cada país os sistemas nacionais de ensino, onde buscava resposta para a questão da formação docente.

O primeiro modelo de formação de professores, como afirma Saviani, “[...] se esgota na cultura geral e no domínio específico dos conteúdos da área de conhecimento correspondente à disciplina que o professor irá lecionar”. A formação didáticopedagógica ainda segundo o autor irá acontecer “[...] em decorrência do domínio dos conteúdos do conhecimento logicamente organizado, sendo adquirida na própria prática docente ou mediante mecanismos do tipo treinamento em serviço" (SAVIANI, 2009, p. 2).

Já no segundo modelo a formação do docente se completa com a eficácia do preparo pedagógico-didático. A instituição formadora além de ofertar uma formação da cultura geral e específica na área de conhecimento correspondente; precisava assegurar de forma deliberada e sistemática através da organização curricular a preparação pedagógico-didática.

O primeiro modelo predominou nas instituições de ensino superior, “[...] que se encarregaram da formação dos professores secundários, ao passo que o segundo tendeu a prevalecer nas escolas normais, ou seja, na formação dos professores primários" (SAVIANI, 2009, p. 2). 
Para tanto, faz-se necessário buscar a história para lembrar que desde o século XVII é acesa a necessidade de pensar a formação de professores, quando esta é preconizada por Comenius que, no mencionado século, pensa na necessidade de elaboração de um método adequado para ensinar a todos com eficiência e eficácia. Mais tarde, já no século XIX, após a Revolução Francesa, é que se inicia o processo de criação de instituições especializadas na formação de professores, quando a instrução popular foi vista como um problema, em suma, pelo seu papel transformador no âmbito da formação de consciência cidadã dos sujeitos (SAVIANI, 2009).

Neste sentido, foi no ano de 1794 na cidade de Paris que a convenção propôs a criação da primeira instituição de ensino, que foi instituída em 1795, com o nome de Escola Normal. Esta, como afirma Saviani (2009), se dividia em "Escola Normal Superior para formar professores de nível secundário e Escola Normal simplesmente, também chamada Escola Normal Primária, para preparar os professores do ensino primário" (SAVIANI, 2009, p. 143).

Segundo Saviani (2009), quando o Norte da Itália foi conquistado por Napoleão, foi instituído em 1802 a Escola Normal de Pisa, cujos moldes se baseavam na Escola Normal Superior de Paris. O seu ensino era destinado para a formação de professores secundários, onde deixou de lado a preocupação com o preparo didático-pedagógico. Também foram instaladas as Escolas Normais ao longo do século XIX nos países como Inglaterra, Itália, Alemanha e Estados Unidos.

No Brasil a questão da formação docente ganhou destaque após a independência, quando foi necessário o investimento na instrução popular, a serviço do modelo de sociedade que se encontrava em construção. Essa preocupação veio aparecer com a Lei das escolas de primeiras letras, publicada em 15 de outubro de 1827, em seu artigo $4^{\circ}$ dizia que os professores deveriam ser formados através do método mútuo (lancasteriano ${ }^{4}$ ) (SAVIANI, 2009).

Essa escola seria administrada por um diretor, que também desempenharia a função de professor e seriam custeados pelas capitais das respectivas províncias. $\mathrm{O}$ seu currículo segundo Tanuri deveria ensinar "ler e escrever pelo método lancasteriano; as

\footnotetext{
${ }^{4}$ Trata-se de um relevante corpus pedagógico criado em Londres no início do século 19 pelo pastor quacker Joseph Lancaster, com a perspectiva de expandir a escolaridade à população empobrecida da Inglaterra. O trabalho de Joseph Lancaster alcançou outros países, dentre eles os Estados Unidos, e na América do Sul, dentre outros, a Venezuela e o Brasil (FERREIRA et al., 2016, p. 01).
} 
quatro operações e proporções; a língua nacional; elementos de geografia; princípios de moral cristã" (TANURI, 2000, p.64). A educação no Brasil nesse período teve várias influências externas, principalmente da França.

Em 1834 foi promulgada a Lei do Ato Adicional, que garantia maior autonomia administrativa às províncias do Império e, "promoveu a descentralização do ensino e a gratuidade da instrução primária”, (NUNES, 2006, p. 24). Essa Lei determinou que fossem implantadas as Escolas Normais brasileiras nas províncias do Rio de Janeiro em 1835 e em Minas Gerais em 1836, que trazia consigo o modelo de ensino francês. Passou a ser exigido segundo Nunes, para o exercício do magistério primário o diploma de normalistas, quem possuía tinha garantido os seus direitos e privilégios (NUNES, 2006).

De acordo com Saviani (2009) essas escolas foram marcadas por possuir trajetórias incertas, sendo fechadas e reabertas diversas vezes. E só obtiveram êxito a partir de 1870 com a concretização das ideias liberais de democratização, obrigatoriedade da instrução primaria e a liberdade de ensino. Antes disso, essas escolas não passaram de um projeto não realizado.

As Escolas Normais visavam o preparo de professores com formação específica para o ensino primário, que deveriam se orientar a partir das coordenadas pedagógicodidáticas. "No entanto, contrariamente a essa expectativa, predominou nelas a preocupação com o domínio dos conhecimentos a serem transmitidos nas escolas de primeiras letras" (SAVIANI, 2009, p. 144). Tinha como propósito em seu currículo as mesmas matérias das escolas de primeiras letras, em que os professores necessitavam do domínio dos conteúdos a que caberia transmitir as crianças, não levando em consideração o preparo didático-pedagógico.

O magistério era visto como uma vocação e não uma profissão, sendo valorizado assim segundo Nunes “[...] a idoneidade moral do professor e seus princípios religiosos do que sua competência teórica e didática, sendo que o peso dessa "história" perdura até os nossos dias" (NUNES, 2006, p. 24).

Desde esse período até a Proclamação da República, várias mudanças aconteceram no Brasil em seu contexto sócio-político e econômico. Surgiram assim, novas demandas para esse novo cenário, que foram provocadas pela necessidade de trabalhadores cada vez mais capacitados para o mercado de trabalho, e como consequência professores habilitados. Dessa forma, houve um avanço na formação desses 
docentes, principalmente na qualificação do ensino profissional (NUNES, 2006).

Essas mudanças também aconteceram nas organizações e funcionamento das Escolas Normais, devido a Reforma da instrução pública das escolas de São Paulo em 1890, que previa segundo Saviani o "[...] enriquecimento dos conteúdos curriculares anteriores e ênfase nos exercícios práticos de ensino, cuja marca característica foi a criação da escola-modelo anexa à Escola Normal - na verdade a principal inovação da reforma" (SAVIANI, 2009, p. 145).

No período de 1920, grandes transformações aconteceram no país, devido ao avanço industrial da sociedade, que antes era de base, eminentemente agrária. Foi através dessas mudanças que a sociedade civil se mobilizou politicamente com campanha para combater o analfabetismo. Em que resultou da implantação em 1924 por educadores brasileiros a Associação Brasileira de Educação. Havia como objetivo reunir professores e pessoas interessadas no estudo e em debater sobre os assuntos referentes à educação pública (NUNES, 2006).

Na década de 1930 segundo Nunes (2006) com a consolidação do capitalismo e a implantação da industrialização no Brasil, criou-se novas demandas educacionais em termos quantitativos, como em termos da própria estruturação do ensino, a fim de que fossem supridas as necessidades emergentes.

Dessa forma, nesse período com o aparecimento de institutos de educação, uma nova fase é aberta na educação, momento em que esta, é encarada não apenas como objeto de ensino, mas vista também como meio de pesquisa. Neste sentido, surgem dois institutos, um deles em 1932 conhecido como Instituto de Educação do Distrito Federal. Idealizado e implantado por Anísio Teixeira e administrado por Lourenço Filho e o Instituto de Educação de São Paulo, implantado por Fernando de Azevedo em 1933 (SAVIANI, 2009).

A reforma estabelecida por Anísio Teixeira, através do decreto n ${ }^{\circ} 3.810$, de 19 de março de 1932, tinha como finalidade romper com a escola tradicional, fundamentada nos princípios da ideologia católica para abrir caminhos para a Escola Nova, em que se pregava que todas as pessoas deveriam ter o direito a educação (NUNES, 2006). Segundo Nunes "[...] reitera-se, a laicidade, a gratuidade e a democratização do ensino", essa reforma também propôs a junção da formação do magistério em nível superior, e ainda conforme mesma autora, o decreto defendia " [...] a erradicação do analfabetismo, a 
priorização do ensino primário e a eliminação do caráter excludente das escolas públicas, frequentadas, em sua maioria, pelos filhos das famílias de classe média" (NUNES, 2006, p. 26).

Poucas alterações aconteceram na formação de professores até a década de 1960. No ano de 1961 foi promulgada a Lei de Diretrizes e Bases da Educação Nacional, que propiciou ao longo dessa década, mudanças através dos Pareceres de nº 251/62 e 252/69 que "[...] indicavam e determinavam que os cursos poderiam formar o professor primário, além dos técnicos e professores da escola normal, desde que fossem introduzidas no currículo as metodologias e práticas de ensino especificas” (GATTI, 2006, p. 112).

Com o golpe militar de 1964, o modelo econômico, que era direcionado para a modernização dos hábitos de consumo e investimentos das classes alta e média, foi reformulado (NUNES, 2006). Essas reformas também atingiram a educação, onde exigiram modificações no campo educacional. Mudanças essas que implicaram em ajustes na legislação do ensino, como a Lei 5.540 aprovada em 28 de novembro de 1968, que reformulou o ensino superior.

Ainda conforme a mesma autora, esta reforma do ensino superior trouxe alguns avanços para a formação docente, momento em que as Faculdades passaram a ser responsáveis pela formação de professores. As licenciaturas passaram a ter tanto a plena duração quanto a curta duração. A nova legislação buscou atender as necessidades do mercado de trabalho com a produção de mão de obra qualificada e uma das primeiras consequências acarretadas ao ensino superior foi a adoção da pedagogia tecnicista, marcado produtividade e a eficiência. Essa reforma também determinou que o ensino superior fosse ministrado em Universidades, e somente em casos excepcionais em estabelecimentos isolados (NUNES, 2006).

O regime militar brasileiro além de representar uma descaracterização do modelo de escola normal, constituiu um quadro de dispersão na questão da formação docente do país. Essa situação levou a um conjunto de iniciativas que objetivavam encontrar novas alternativas para os cursos de licenciatura. Houve expectativas de que com o fim do regime militar e a posse de um presidente, em 1985, esses problemas pudessem ser então solucionados (SAVIANI, 2009).

A nova Constituição do país, promulgada em 05 de outubro de 1988, incorporou vários dispositivos que contemplavam algumas reivindicações dos professores e 
mantinha o dispositivo que conferia à União competência exclusiva para legislar sobre diretrizes e bases da educação nacional. Para que fosse cumprido esse dispositivo em dezembro de 1988 deu-se início a uma proposta de tramitação de elaboração de novas diretrizes e bases da educação nacional, chegando-se, após diversas mudanças, à Lei n. 9.394, promulgada em 20 de dezembro de 1996 (SAVIANI, 2009).

O Brasil nesse ano, contava com "5.276 Habilitações Magistério em estabelecimentos de ensino médio, das quais $3.420 \mathrm{em}$ escolas estaduais, $1.152 \mathrm{em}$ escolas particulares, 701 em escolas municipais e 3 federais” (TANURI, 2000, p. 85). Em nível superior contava-se, no ano de 1994, com 337 Cursos de Pedagogia, sendo 239 particulares, 35 federais, 35 estaduais e 28 municipais. Sendo assim a formação de professores da Educação Infantil e das quatro primeiras séries do Ensino Fundamental era, na sua maioria, efetivada em nível médio (SAVIANI, 2009).

Diante desse contexto, o artigo 62 da nova Lei de Diretrizes e Bases da Educação Nacional (LDB) esclarece que o profissional para atuar na educação básica, que abrange a Educação Infantil, o Ensino Fundamental e o Ensino Médio, precisaria ter o Ensino Superior. A nova lei exigia o Ensino Superior a todos os tipos de formação de professores, o que significaria, na prática, passar ao nível superior a formação de professores da educação infantil e das quatro séries iniciais que antes eram realizadas, predominantemente, em nível médio (SAVIANI, 2009).

Contudo segundo Saviani (2009) a preocupação com a aprendizagem profissional da docência está diretamente ligada com a preocupante melhoria da qualidade da educação, visto que a formação de professores é elemento fundamental para sua ocorrência. Essa aprendizagem deve ser vista como um processo complexo e contínuo. Permeado por oscilações e descontinuidades, sendo a experiência pessoal e a prática profissional importantes fatores para a construção da mesma.

A aprendizagem docente não deve funcionar apenas como um processo de substituição de conhecimentos. É ingênuo pensar que o professor que esteja em contato com vários fundamentos disciplinares, possa ser capaz de transmiti-los para o seu contexto profissional. O que mostra que os professores são elaboradores de conhecimentos profissionais, sendo assim profissionais que devem possuir autonomia na condução de seu trabalho.

Entretanto, essa autonomia é tida por vezes relativa, visto que, muitas vezes seu 
trabalho é determinado por requisitos já existentes. Requisitos esses que podem ser desvelados por meio dos elementos estudados na disciplina História da Educação. Que por sua vez ao serem estudados podem auxiliar os professores a conhecerem os mecanismos em que foram produzidos e consequentemente os interesses políticos, econômicos e ideológicos que os impulsionam.

\section{Uma abordagem sobre o ensino de História da Educação Brasileira}

A disciplina História da Educação sempre esteve presente nos cursos de formação de professores, com centralidade especial no currículo dos cursos de Pedagogia desde a sua criação; sendo sua formação intensamente marcada pelos estudos históricos, e se configurou como campo predominantemente investigado por pesquisadores da área da educação. Desse modo, dialoga-se aqui, a respeito da introdução dessa disciplina nestes cursos de formação de professores na educação brasileira.

A História da Educação é historicamente marcada por fazer parte das disciplinas dos cursos de formação de professores. Desde século XIX podemos perceber a presença da disciplina História da Educação nas universidades e escolas normais disseminadas pelo mundo, chegando também ao Brasil (CARVALHO, 2005).

Diante das colocações acima, faz necessário ponderar que no Brasil o momento mencionado foi marcado por uma monarquia constitucional católica, onde a educação era voltada para os ideários revolucionários franceses do século XVIII. Dessa maneira, a educação era um processo extremamente elitista.

Neste sentido, nasceu a primeira escola normal brasileira em 1835, na província do Rio de Janeiro, porém não se consolidou, findando suas atividades em 1849. O currículo dessa escola era voltado para a instrução primária, e a oferta dos seus conteúdos era dividida da seguinte forma: as quatro operações e proporções, ler e escrever pelo método lancasteriano, elementos de geografia, língua nacional e princípios da moral cristã. Não havendo a presença da disciplina História da Educação, o que possibilitou um distanciamento das ciências da educação (GATTI JUNIOR, 2006).

Tendo em vista o exposto, vale salientar, que somente em 1928 a disciplina História da educação integrou o currículo dos cursos de magistérios nas Escolas Normais brasileiras. A Escola Normal do Distrito Federal do Rio de Janeiro passou por uma reforma em 1932 regida por Anísio Teixeira. Em 1933 a Escola Normal de São Paulo 
também foi reformulada através de Fernando de Azevedo, sendo proposto por ele que "a história da educação será incluída, sob a forma de disciplina "História e Filosofia da Educação", no currículo instituído em 1946, para todas as Escolas Normais do país, pela Lei Orgânica do Ensino Normal” (SAVIANI, 2005, p. 49).

E com intuito de atender a demanda, surgiram nessa época, manuais dos conteúdos básicos que deveriam ser ministrados na disciplina História da Educação pelos professores normalistas, onde trazia uma escrita totalmente moralizadora. Esta disciplina tinha somente a função formadora, onde os seus conteúdos traziam ethos religiosos e salvacionistas.

Com a reforma da instituição pública no Distrito Federal em 1932, Anísio Teixeira "[...] deixou clara a intenção de erradicar aquilo que ele considerava como "vicio de constituição" das Escolas Normais" (SAVIANI, 2005, p. 50). Assim, ele traçou um plano a ser introduzido nas Escolas Normais que teria os Cursos de Fundamentos Profissionais, Cursos Específicos de conteúdo profissional e cursos de integração profissional, nos quais somente a última modalidade abrangeria a disciplina História da Educação associada à Filosofia da Educação.

Desta forma, com o decreto de Capanema é possível observar que o currículo do "[...] curso de Pedagogia incluía História da Educação no segundo e terceiro anos e Filosofia da Educação apenas no terceiro ano sendo, pois, tratadas como duas disciplinas distintas e autônomas entre si" (SAVIANI, 2005, p. 51). Sendo assim, essa reformulação perpetuou nas reformas anteriores e mantendo-se até os dias atuais.

De antemão, considera-se importante esclarecer o entendimento de que historicamente atrelada a programas institucionais de formação de professores, a disciplina História da Educação ocupou-se de modo recente com um saber subsidiário. Seu currículo funcionava na condição de um vestíbulo introdutório de outros estudos, com a preocupação de fornecer somente o contexto e a origem de uma determinada questão, estudada por pesquisadores de outras "ciências" da educação, reconhecidos como pessoas mais autorizadas (CARVALHO, 2005).

Dos períodos anteriores até a década de 1960 não houve muitas alterações na formação de professores no Brasil. Com a promulgação da Lei de Diretrizes e Bases da Educação em 1961, aconteceram algumas mudanças no que diz respeito a esta formação. Ela determinava que os cursos poderiam formar professores primários, técnicos e 
professores da Escola Normal, mas em seus currículos de ensino deveriam ser introduzidas as metodologias e práticas específicas (GATTI JUNIOR, 2006).

A disciplina História da Educação está presente nos currículos do curso de Pedagogia desde o seu início até a década de 1960, onde a formação do pedagogo era marcada pelos estudos históricos, primeiramente pelos estudos da história das doutrinas pedagógicas e ficando em segundo plano o estudo da História da Educação como fato social (SAVIANI, 2005).

Outro aspecto importante no que diz respeito ao ensino de História da Educação no Brasil, foi a criação, na década de 1960, de programas de pós-graduação em educação, momento em que a disciplina ganhou espaço no currículo de formação dos cursos, passando, desse modo, a encontrar escopo no âmbito da formação de professores no país.

Na década de 1970, com a Lei $n^{\circ} 5.692 / 71$ foi introduzida "à profissionalização obrigatória no ensino de segundo grau" (GATTI JUNIOR, 2006, p. 112), incluindo-se assim, as habilitações pedagógicas para o magistério (Administração, Inspeção, Orientação e Supervisão educacionais), também ocorreram algumas mudanças no currículo do curso com o Parecer n. 253 de 1969, do então Conselho Federal de Educação, e uma deles foi a reeducação semestral dessa disciplina de seis a oito semestres para dois ou três no máximo (SAVIANI, 2005).

Segundo Júnior e Galvão (2005), a História da Educação no Brasil, por muito tempo, se ocupou em estudar a organização dos aparelhos de ensino, de ideário e discursos pedagógicos, que tinha por base as leis, as reformas educacionais, os regulamentos e as obras de grandes estudiosos. Por estar muito próxima à Filosofia da Educação, os estudos da história se tornaram em algumas vezes, estudos das recomendações, havendo pouco tratamento, do cotidiano escolar e de suas práticas.

Percebe-se assim, o quanto o lugar ocupado pela disciplina de História da Educação e pelo conteúdo ensinado nessa disciplina ao longo da trajetória histórica da formação docente na tradição da universidade brasileira vem consistindo em um espaço inadequado às contribuições que esta pode oferecer à formação do professor.

Salienta-se a observação de que a disciplina História da Educação vem sendo trabalhada em uma perspectiva da historicidade formativa ${ }^{5}$. Deste modo, compreende-se

\footnotetext{
${ }^{5}$ Compreende-se por historicidade formativa, o estudo de conteúdos que abordem a história dos sujeitos políticos (o estado), a história política, e a história das intenções dos sujeitos civis, por estar centrados nos
} 
que essa concepção permanece presente na prática de alguns profissionais que, de forma consciente ou não agem aos moldes do positivismo. Muitas vezes essa prática aparece disfarçada nos discursos que representam uma tendência totalmente contrária. Em que também os trabalhos realizados no campo da História da Educação deixavam mais evidentes a história política, a história dos sujeitos políticos. Nesse caso o estado e a história das intenções dos sujeitos civis (JÚNIOR e GALVÃO, 2005).

Todavia, ressalta-se que nos últimos vinte anos no Brasil, a História da Educação passou por um processo renovação, o campo de pesquisa se aproximou de uma nova maneira de escrever a história, que possibilitou uma nova leitura do seu campo de atuação. Segundo Carvalho "a história da educação se multiplica em uma pluralidade de domínios — história das disciplinas escolares, história da profissão docente, história do currículo, história do livro didático etc." (CARVALHO, 2005, p. 35).

Ainda conforme Júnior e Galvão (2005), esse processo de renovação e ampliação da historiografia da História da Educação Brasileira encontrou inspiração, sobretudo, na escola dos Annales, com a intenção de entender e escrever uma nova história no campo da educação, o qual seu objetivo era voltado para a investigação das práticas culturais e, também, influenciados em parte pela renovação marxista.

Segundo Saviani (2000) nas últimas décadas os estudiosos desta área têm lutado no sentido de adquirir competências no âmbito historiográfico, com o intuito de estabelecer um diálogo com os historiadores. Daí surge a necessidade de se tornar uma disciplina independente, pois até então se encontrava presa à Filosofia e até mesmo da Teologia, era entendida como afirma Saviani “"...] como uma disciplina pedagógica de caráter normativo e doutrinário a serviço da formulação dos ideais educativos, antes que como um ramo das ciências da educação cuja tarefa seria a explicitação das condições em que se desenrola o fenômeno educativo" (SAVIANI, 2000, p. 02).

Neste sentido, o campo da historiografia tem buscado evidenciar a historicidade do lugar social, onde o historiador lança um novo olhar sobre as fontes que está sendo pesquisada, interrogando o arquivo que está sendo estudado. Assim, “[...] a História da Educação passa a tematizar a perspectiva dos sujeitos dos processos investigados, trabalhando com as representações que os agentes históricos fazem de si mesmo, de suas

processos históricos de maneira linear e cronológica, que seguem os modelos de ensino positivista. Esta formação não possibilita uma problematização a respeito dos objetivos educacionais e suas contradições em diferentes contextos históricos. 
práticas, das práticas de outros agentes" (CARVALHO, 2005, p. 35).

Estudar a História da Educação, segundo Manacorda (2006), possibilita uma problematização dos objetivos educacionais nos diferentes períodos históricos e, também, como foi formada a relação entre esses objetivos e a realidade educativa, bem como suas contradições. Mas o fato é que dependendo da forma como está é ensinada, ela pode ser submetida a estratégias políticas com o objetivo de negar aos futuros profissionais da educação o direito de terem uma formação crítica.

Neste sentido, Neves (2003, p. 7) afirma que "as ementas, os objetivos, os programas e conteúdo, bem como as referências bibliográficas acabam por configurar um determinado perfil da disciplina. Perfil este que, também, se explica pela formação dos profissionais que nela atuou".

Essa disciplina transita nos cursos de graduação e pós-graduação dos cursos de formação de professores. Alvo de crítica por alguns autores como Saviani (2009), Nunes (2006), Carvalho (2005), dentre outros, pela função de consolidação ou subsistência que ela recebe nos seus programas de ensino. Pois a sua consolidação indica uma junção de vários fatores que "a História da Educação como saber especializado, autônomo e reconhecido. Nesse processo, são considerados a carga horária, os objetivos, as ementas e a matriz a que está filiada" (BORGES e GATTI, 2011, p. 04).

De acordo com o entendimento acerca da temática até então, compreende-se que a oferta da disciplina História da Educação nos cursos de formação de professores em geral é de caráter obrigatório, sendo ofertada em regime semestral e com carga horaria média de $120 \mathrm{~h}$. Os seus conteúdos giram em torno de manuais de ensino que de acordo com Borges e Gatti “uma das questões básicas é o tratamento do conteúdo tido em muitas vezes como denso, fastidioso, enciclopédico" (2011, p. 19).

Assim, entende-se que a disciplina História da Educação é, comumente, trabalhada com uma carga horária reduzida, uma vez que, os conteúdos são vistos em uma perspectiva de história positivista, de forma linear e cronológica, onde há poucas pesquisas na área de educação desenvolvidas dentro desses cursos de formação.

Diante das colocações acima, continuaremos nossas reflexões, abordando a respeito do valor atribuído a esta disciplina dentro dos cursos de formação docente. 


\title{
4 A importância da disciplina História da Educação para a formação de professores
}

Discutir acerca do valor atribuído à disciplina História da Educação requer ressaltar aqui que a educação e sua história são construídas ao longo da existência humana, pois desde que o homem habita o planeta e nele se relaciona, pressupõe-se a presença do processo educacional, mesmo que informal, mas ainda assim, um processo educacional.

Dessa forma, compreende-se a importância de se estudar a história de um modo geral, e aqui nesse caso a História da Educação está na possibilidade de subsidiar as variadas análises e compreensões com embasamento teórico de suas origens no decorrer da evolução dos fatos e fenômenos sociais que produzem e compõem o percurso histórico da educação de modo integral, com subsídios categóricos para construção de novas práticas e saberes.

Neste sentido, o conhecimento da História da Educação no âmbito da formação de professores se faz necessário para resgatar a história que produziu, que continua a produzir a realidade educacional no decorrer da evolução da vida humana.

\begin{abstract}
Por isso, é importante estudar a educação sempre no contexto histórico geral, para se observar a concomitância entre as suas crises e as do sistema social. Esta sincronia não deve ser entendida apenas como simples paralelismo entre fatos da educação e fatos sociais. Na verdade, as questões de educação são engendradas nas relações que os homens estabelecem ao produzir sua existência. Nesse sentido, a educação não é um fenômeno neutro, mas sofre os efeitos da ideologia, por estar de fato envolvida na política. (ARANHA, 1996, p. 19).
\end{abstract}

Entende-se então que a disciplina História da Educação consiste em um potencial que poderá contribuir para o desenvolvimento de uma visão mais crítica da educação através de análise dos processos que produziram as práticas pedagógicas e do processo sócio-histórico, fazendo com que tais práticas sejam desnaturalizadas, enfatizando sua intima relação com o contexto em que estão inseridas.

Todavia, ressalta-se que a História da Educação pode ajudar o profissional em formação a ter uma consciência mais crítica do processo educacional, pois permite que os problemas educativos sejam abordados de forma mais transparentes possibilitando uma melhor compreensão do desenvolvimento da sociedade e da classe social dominante.

Essa disciplina também oferece um espaço de reflexão sobre as práticas 
educativas, de modo a fundamentar decisões que possam superar o estado acrítico que foi imposto pela ideologia dominante. Para isso, é necessário mais que a ampliação da carga horária, faz-se necessário a valorização da disciplina, tendo por base a formação de professores numa concepção integral e que vá de encontro à construção aprimorada do conhecimento, de forma que o professor tenha condição de transmitir o conteúdo e ao mesmo tempo estimular o aluno a ter uma visão mais reflexiva e crítica da sociedade, podendo assim formá-lo dentro de uma perspectiva da historicidade crítica.

Os cursos que contam com a disciplina em questão em seus currículos têm uma maior e mais sólida fundamentação para discutir os diferentes momentos históricos e a organização educacional dentro desses diferentes contextos. A partir daí, a percepção e o conhecimento dos desafios que a realidade social impõe aos professores, enquanto profissionais que questionam, problematizam e procuram possibilidades; nessa procura, depara-se com as contradições postas pelas políticas que influenciam na vivência do dia a dia.

Diante da situação aqui explicitada, os cursos de formação de professores que contém em seus currículos a disciplina de História da Educação poderá oferecer aos seus acadêmicos um suporte tanto quantitativo, quanto qualitativo, necessário na formação docente, além de proporcionar uma real participação e interação a partir de uma perspectiva crítica para a elaboração, organização e atualização dos instrumentos democratizadores da escola.

Esse pressuposto é fundamentado no fato de que o estudo aprofundado da História da Educação propícia uma contribuição que "é importante para dar carne e sangue às representações e às explicações históricas de eventos e estruturas" (SANFELICE; SAVIANI; LOMBARDI, 1999, p. 35), de forma que esse conhecimento dê base para as ações e proposições docentes de modo a construir um ambiente e uma educação escolar que forme sujeitos capazes de interferir positivamente a sociedade em que está inserido.

\section{Considerações finais}

Neste sentido, por meio dos estudos feitos sobre essa disciplina percebe-se que a História da Educação sempre esteve arraigada nos cursos de formação de professores desde o século XIX, momento em que permaneceu associada em primeiro momento com a Filosofia da Educação, e que mais tarde foram tratadas como duas disciplinas distintas. 
Ela compôs por muito tempo o currículo das Escolas Normais Brasileiras, com centralidade no curso de Pedagogia, desse modo, a formação do pedagogo sempre esteve fortemente marcada pelos estudos históricos (SAVIANI, 2005).

O estudo desta disciplina contribui para a compreensão da realidade, pois ela tem um grande potencial, visto que dar_subsídios para problematizar os objetivos educacionais nos diferentes períodos históricos. Mas dependendo da maneira como é atribuída dentro dos cursos de formação de professores poderá contribuir positivamente ou negativamente.

Pois, a estrutura curricular dos cursos que ofereciam essa disciplina, visava o seu ensino em período anual. Mas, devido às mudanças acontecidas no final da década de 1990, passou a ser estudada em regime semestral. Através das leituras, percebe-se também uma redução da carga horária dela de uma década para outra. A respeito disso, Borges e Gatti afirmam que “[...] às pressões por cursos de formação em tempo cada vez mais reduzido, caracterizando uma formação aligeirada, recorrendo em muitas vezes, à diminuição de carga horária das disciplinas” (BORGES e GATTI, 2011, p. 19).

Desse modo, compreende-se que o campo do conhecimento da História da Educação é marcado pelo modelo pragmático, pois a partir dos autores aqui estudados, entende-se que os conteúdos estão centrados nos processos históricos de maneira linear. Assim, essa disciplina vem sendo trabalhada na perspectiva da historicidade formativa, pois os conteúdos abordados nas ementas desta disciplina deixam evidente o estudo da história dos sujeitos políticos (o estado), a história política, e a história das intenções dos sujeitos civis, entende-se então que seguem os modelos de ensino positivista.

Pois, conforme Borges e Gatti, contam com conteúdos programáticos, em sua maioria, seguidas por uma lógica ora cronológica, ora espacial, “[...] apresentado em espaço limitado de tempo dedicado à disciplina, muitas vezes, sob a abordagem linear da história da educação que obriga percorrer, segundo a ordem cronológica" (BORGES e GATTI, 2011, p. 19). Sua sequência se pauta em temas e momentos clássicos da historiografia educacional brasileira, onde abordam assuntos que seguem uma temporalidade da história política, desde Brasil Colônia até a atual LDB.

Nessa perspectiva, o ensino da História da Educação acaba por negar ao futuro profissional uma formação mais crítica. Visto que, por vezes sua materialização, não possibilita uma problematização arraigada a respeito dos objetivos educacionais e suas contradições em diferentes contextos históricos. Assim, se as ementas, os conteúdos, a 
carga horária e todo o programa de ensino não forem abordados de forma que deem condições para uma discussão da história em uma perspectiva ampla, acaba por configurar o perfil do profissional que irá se formar, e, consequentemente, tem-se um entendimento do perfil do profissional que lecionou essa disciplina (NEVES, 2005).

Dessa forma, a disciplina História da Educação tem um grande desafio, pois precisa modificar esse modo de ensinar a história que foi introduzido nas práticas pedagógicas dos cursos de formação de professores, de maneira que “[...] se torne transformadora da consciência e da ação educativa pela via do conhecimento histórico" (BORGES e GATTI, 2011, p. 19).

Compreende-se, que os cursos de formação de professores que contam com esta disciplina na sua estrutura curricular, com conteúdos que abordem a história em sua totalidade, proporciona ao futuro professor uma melhor fundamentação para discutir diferentes momentos históricos e a organização educacional dentro de diversos contextos.

Tendo em vista todos os elementos que foram abordados aqui, entende-se que conhecer o passado ajuda na construção do presente, e que a História e a História da Educação, se estudadas dentro de perspectiva da historicidade crítica podem contribuir na formação histórica dos homens.

Conclui-se almejando que todas essas reflexões possam contribuir para um novo modo de se pensar a História da Educação. Entende-se que essa é uma disciplina imprescindível nos cursos de formação de professores, pois coloca em evidência questões indispensáveis à formação docente de forma consciente. Ela também aproxima e dialoga com outros componentes do currículo desses cursos. Espera-se ainda, que esta pesquisa colabore para o avanço de novos estudos no âmbito dos cursos de formação de professores.

\section{Referências}

ABREU, Rudimar Serpa de. O Ensino de História e sua Historiografia. Revista Eletrônica da Ulbra são Jerônimo - v. 01, 2007.

ARANHA, Maria Lúcia de Arruda. História da Educação. São Paulo: Moderna, 1996.

ARRUDA, Maria Aparecida. História da Educação: ensino e pesquisa. Belo Horizonte: Autêntica, 2006, p. 107-122.

BACELLAR, Carlos. Uso e mau uso dos arquivos. In: PINSKY, Carla Bassanezi. Fontes 
Históricas. São Paulo: Contexto, 2005, p. 23-72.

BORGES, Bruno Gonçalves. GATTI JUNIOR, Décio. A disciplina História da Educação no Brasil: presença e formas de organização. IX Encontro Interno e VIII Seminários de Iniciação Científica. UFU, 2009.

BORGES, Bruno Gonçalves. GATTI JUNIOR, Décio. O ensino de História da Educação na formação de professores no Brasil atual. Revista HISTEDBR On-line, Campinas, n.40, p. 24-48, dez. 2010.

BORGES, Vavy Pacheco. O que é história. 2ed. São Paulo: Brasiliense, 1993.

BURKE, Peter. A Escola dos Annales (1929-1989): a Revolução Francesa da historiografia. São Paulo: Ed. da UNESP, 1997.

CARVALHO, Marta Maria Chagas de. Considerações sobre o Ensino de História da Educação no Brasil. In: GATTI Jr., Décio e INÁCIO FILHO, Gerando. (Org.). História da Educação em Perspectiva: ensino, pesquisa, produção e novas investigações. Campinas/SP: Autores Associados. Uberlândia/MG: Editora da Universidade Federal de Uberlândia. p. 33-45, 2005.

FENELON, Dea. Pesquisa em História: perspectiva e abordagens. In: FAZENDA, Ivani. Metodologia da pesquisa educacional. 3 ed. São Paulo: Cortez, 1994, p. 117-136.

FERREIRA, Dirce Nazaré de Andrade; SCHWARTZ, Cleonara Maria; KROHLING, Aloisio. $O$ método de ensino lancasteriano: Uma comparação entre a sala monitoral do the british school museum de hitchin, na inglaterra, e o regimento interno das aulas públicas das primeiras letras da província do espírito santo em 1871. História da Educação [online]. 2016, v. 20, n. 48 [Acessado 9 Junho 2021] , pp. 175-191. Disponível em: <https://doi.org/10.1590/2236-3459/41842>.

GATTI JUNIOR, Décio. Estudo sobre o processo de constituição do ensino e da pesquisa em História da Educação no Brasil. In: MORAIS, Christianni Cardoso; PORTES, Écio Antônio; ARRUDA, Maria Aparecida. História da Educação: ensino e pesquisa. Belo Horizonte: Autêntica, 2006, p. 107-122.

GATTI JUNIOR, Décio. Percursos e desafios da pesquisa e do ensino de História da Educação. Uberlândia: EDUFU, 2007.

ISKANDAR, Jamil Ibrahim; LEAL, Maria Rute. Sobre positivismo e educação. Revista Diálogo Educacional. Curitiba. v. 3, n.7, p. 89-94, set./dez. 2002.

JÚNIOR, Dilceu Roberto Pivatto. MARXISMO E ENSINO DE HISTÓRIA: práxis do conhecimento e Formação do sujeito crítico-social. Revista Semina, V9 - n 1, 2010, publ. no $1^{\circ}$ sem. 2011.

JÚNIOR, Marcílio Souza; GALVÃO, Ana Maria de Oliveira. História das disciplinas escolares e história da educação: algumas reflexões. Educação e Pesquisa. São Paulo, v. 31, n. 3, p. 391-408, set./dez. 2005.

MANACORDA, Mário Alighiero. História da Educação: da antiguidade aos nossos dias. 12 ed. São Paulo: Cortez, 2006. 
MARTINS, Estevão de Rezende. Cultura, ciência, teoria e filosofia. Revista de Filosofia. Puplicado 30 de Agosto de 2004.

MATOS, Júlia Silveira. Tendências e Debates: da escola dos Annales à História Nova. Historiae, Rio Grande, v.1 p.13-130, 2010.

NEVES, Fátima Maria. História da Educação no Brasil - Considerações historiográficas sobre a sua constituição. In: ROSSI, E. R.; RODRIGUES, E. \& NEVES, F. M. (Org.) Fundamentos históricos da educação no Brasil. Maringá: EDUEM, 2005.

NORONHA, Olinda Maria. História da educação: sobre as origens do pensamento utilitarista no ensino superior brasileiro. Campinas/SP: Editora Alínea, 1998.

NUNES, Magda Soares. Políticas para a formação e profissionalização de professores para o ensino superior: a contribuição do PROSUP. Tese de Mestrado - Pontifícia Universidade Católica de Minas Gerais: Belo Horizonte, 2006, p. 23-35.

RODRIGUES, Rosângela Silveira. Didática e educação de educadores: uma articulação dialética. Montes Claros: Unimontes, 2002, p.25-47.

SANFELICE, José Luiz; SAVIANI, Dermeval; LOMBARDI, José Claudinei. História da Educação: perspectivas para um intercâmbio internacional. Campinas, SP: Autores Associados: HISTEDBR, 1999.

SAVIANI, Dermeval. A situação atual da educação e a formação de professores para a educação básica no brasil. Conferência de abertura do XVII Seminário Internacional sobre formação de professores para o MERCOSUL - CONESUL. Porto Alegre, 3 de novembro de 2009.

SAVIANI, Dermeval. Formação de professores: aspectos históricos e teóricos do problema no contexto brasileiro. Revista Brasileira de Educação. v. 14 n. 40 jan./abr. 2009.

SAVIANI, Dermeval. História da História da Educação no Brasil: um balanço prévio e necessário. EcosS Revista Cientifica. São Paulo, v.10, nº especial, p.147-167, 2008.

SAVIANI, Dermeval. Ensino, pesquisa e organização na formação do campo da História da Educação Brasileira. In. MONARCHA, Carlos. História da Educação Brasileira: formação do campo. $2^{\mathrm{a}}$ ed. Ijuí, RS: Unijuí, 2005, p.49-75.

TANURI, L. M. História da formação de professores. Revista Brasileira de Educação, n. 14, maio-ago 2000, p. 61-88.

TANURI, L. M. História da formação de professores. Revista Brasileira de Educação, n. 14, p. 61-68, maio/ago., 2000.

THOMPSON, E. P. A miséria da Teoria (ou um planetário de erros). Rio de Janeiro: Zahar Editores, 1981.

WARDE, Mirian Jorge. Contribuições da História para a educação. Em Aberto, Brasília, 1999. p. 3-11. 